\title{
Influence of number of catalytic sites in 1,3-butadiene solution polymerizations catalysed by titanium tetrachloride
}

\author{
Renan Lopes ${ }^{1}$, Mateus Vasconcelos ${ }^{2}$, and Amanda Brandão ${ }^{1}$ \\ ${ }^{1}$ Pontifical Catholic University of Rio de Janeiro \\ ${ }^{2}$ UFRJ
}

May 5, 2020

\begin{abstract}
The synthetic rubber industry is of great importance and it is present in the daily life of world society. BR (butadiene rubber or polybutadiene) is one of the most used polymers in this field, mainly in tire production. Therefore, the control of operational conditions and final properties of the polymer formed are important points to be studied as they are a challenge for the industry. Thus, the present work focus in simulate the batch polymerization of polybutadiene using the Aspen Plus software, where 1,3-butadiene, titanium tetrachloride, triethylaluminium and hexane were used as monomer, catalyst, co-catalyst and solvent, respectively. Four cases were simulated changing the number of catalyst sites in order to predict and compare the final properties of polybutadiene resins including the average molecular weights, the molecular weight distribution and the evolution of operation conditions that are used at plant to monitor the course of the reaction like the reaction temperature and pressure.
\end{abstract}

\section{Hosted file}

Manuscript Polybutadiene.pdf available at https://authorea.com/users/296096/articles/424945influence-of-number-of-catalytic-sites-in-1-3-butadiene-solution-polymerizationscatalysed-by-titanium-tetrachloride 